У,

ББК 67.9

DOI 10.22394/1682-2358-2021-6-52-61

S.S. Kbusainova, postgraduate student of the World Politics Department, Saint-Petersburg State University

\section{SELF-DETERMINATION OF INDIGENOUS PEOPLES \\ IN RUSSIA, CANADA AND NORTHERN EUROPE: \\ COMPARATIVE ANALYSIS}

The phenomenon of indigenous peoples' societal security in the context of the northern countries foreign policy instrument in the Arctic is studied. The author proves the fragmentation of the legal framework of the domestic legislation of states, which is an obstacle to intercultural dialogue.

Key words and word-combinations: self-determination, indigenous peoples, identity, societal security.
С.С. ХусаиноВа, аспирант кафедрь мировой политики Санкт-Петербургского государсmbенногоуниверситета (email: selenis95@mail.ru)

\section{САМООПРЕАЕАЕНИЕ KOPEHHЫХ МААОЧИСАЕННЫХ} НАРОАОВ РОССИИ, КАНААЫ И СЕВЕРНОЙ ЕВРОПЫ: СРАВНИТЕАЬНЫЙ АНААИЗ

Аннотация. Исследуется феномен социетальной безопасности коренных малочисленных народов как инструмента внешней политки северных стран на территории Арктики. Доказывается разрозненность нормативно-правовой базы внутреннего законодательства государств, являющаяся препятствием для межкультурного диалога.

Ключевые слова и словосочетания: самоопределение, коренные малочисленные народы, идентичность, социетальная безопасность.

M тике - акутамьное направление внешней политики Российской ФеАерации, избранной председателем Арктического совета на 2021-2023 гг. Ответственное управление Арктикой закмючается в четкой госуАарственной политике, связанной с продвижением комлективных Подходов к обеспечению устойчивого развития региона при соблюдении баманса во всех сферах жизнедеятельности. Вопрос о самоопределении коренных малочисленных народов, несмотря на 
уже существующие обширные законодательные базы Российской Федеращии, Канады и стран Северной Европы, все еще вызывает трудности.

Проблема самоопределения коренного малочисленного населения усможняется тем, что в ряде стран, имеющих регионацьные особенности, но претендующих на звание правовых с ориентацией на благоденствие и равноправие, не обеспечивается в равной степени социетальная безопасность. Затруднение в самоидентификации возникает относительно территориального вопроса о принадлежкности земель, площади которых превосходят запросы городского населения, так как традиционные промыслы, жизенно необходимые коренному населению, реализуются на масштабных землях. В современных международных условиях вопрос о праве коренного малочисленного народа на самоопределение явмяется не только предметом ассимицяџии и соџиетальной безопасности, но становится серьезным вызовом, способным повлиять на ситуацию с вмадением арктическими территориями.

В настоящее время на территории Российской Федерации прожкивают такие коренные малочисленные народы, как абазины (Карачаево-Черкесская Республика), алеуты, алюторџы (Камчатский край), бесермяне (УАмуртская Республика) и иные (в алфавитном порядке), согласно Аанным Всероссийской переписи населения 2010 г. [1]. Постановмением Правительства РФ от 24 марта 2000 г. № 255 установлен Единый перечень коренных малочисленных народов с изменениями и дополнениями от 13 октября 2008 г. № 760, 18 мая 2010 г. № 352, 17 июня 2010 г. № 453, 2 сентября 2010 г. № 669, 26 декабря 2011 г. № 1145, 25 августа 2015 г. № 880. Сегодня коренные малочисленные народы России составляют прмерно 0,3\% от обшего населения страны [2].

В европейском измерении ситуация иная. Так, этнический состав Королевства Норвегия достаточно однороден - в стране проживает мишь один коренной малочисленный народ - саамы, которые составмяют около $1 \%$ от общего населения государства [3]; в Королевстве Швеция саамы составмяют примерно 0,3\% [4] ; в в этногенезе Аании имеются представители этнических меньшинств - инуитов, фарерџев и фризов, передвигающихся по Фарерским островам, поэтому опредемить их количество достаточно сложно. Уникальную ситуацию демонстрирует Канада, этногенез которой сформирован в ходе исторического процесса, и коренное малочисленное население в государстве составцяет более 4,5\% от всего населения страны [5] .

Проблема самоопределения коренных малочисленных народов Крайнего Севера Российской Федераџии не ограничивается вопросом самоидентификации в Арктическом регионе, на защиту самовыражения нередко не имеют возможности рассчитывать многие национальные меньшинства, населяющие страну. Речь не идет о соџиальных нормах или 
благах, предоставляемых Правительством РФ, так как на них может рассчитывать мюбой гражкданин страны, более того, коренные народы обладают Аополнительной социальной подАержккой. Проблемы кроются гораздо глубже и представмяют собой серьезную угрозу не только Аля внутриполитического строя в определенных регионах, но явцяются ключевым фактором в межАународной политике как вызов суверенитету государства.

Социетальная безопасность - понятие в трактовке Копенгагенской школы исследований безопасности, раскрывает «способность общества сохранять свою сущность в изменяющихся условиях при возможных или явных угрозах», что в корне меняет дискурс межнациональной помитики [6] . Аихотомия нового времени порожАается отсутствием гонки вооружений и мировых мидеров, готовых к политическому противостоянию; вместе с тем количество потенциально опасных и нестабильных политических акторов растет. ОАнако парадигма международной безопасности видоизменилась, усиление интеграционных движений, а также вопросы самоопределения выявцяют невидимые ранее политические вызовы и угрозы [7]. Полемика о праве на самоопределение коренных малочисленных народов стран мира крайне актуальна.

Специфика работы в этнической сфере заключается прежде всего в преодолении нетерпимости к своему собственному происхождению, а также ксенофобии в регионах, на территории которых проживают национальные меньшинства. Отсутствие духовно-нравственного воспитания перекладывает на плечи узкого семейного круга ответственность за преАопределение идентичности подрастаюшего поколения. Организуемые мероприятия, как правицо, касаются определенных мюдей, что не дает возможности Аругим гражданам узнать о существовании малочисленного народа, чей язык и самоидентификация находятся под угрозой [8] . Таким образом, традиционная культура малых этносов автоматически находится в вакууме, не имеет характера массовости и, как следствие, не популяризируется, что порождает отрицание важности сохранения их самобытного сушествования, вынуждая молодое поколение отказываться от своей истории. Это порождает эффект замацчивания и превращения малых наций в нации, не имеющие голоса, в скрывающиеся субнации.

Государственная социальная политика Российской Федерации преАусматривает опредеменные общественные блага дмя представитемей коренных малочисленных народов, к примеру, целевые бюджетные места Амя обучения в учебных учреждениях, предоставление мьгот и пособий для поддержки существования национальных меньшинств [9] . Такая ситуация порождает парадокс: молодое поколение уезжает из регионов и территорий самобытного проживания, вцивается в современное общество, которое по уровню развития гораздо привлекатель- 
нее, чем жизнь в отдаленном регионе. Подобная ситуация характерна Аля многих регионов Российской Федерации.

Явцение социетальной безопасности доказывает, что коренные малочисленные народы Российской Федерации находятся в риске исчезнования или утери своих национальных особенностей, чего нельзя допускать, если руководствоваться Основным Законом страны, в котором прописано право многонационального народа [10]. Оосбенность создавшегося положения в том, что при отсутствии явных угроз сушествованию самобытности, медленная ассимилящия коренного малочисленного народа со структурообразующим быма бы могичным и естественными проџессом, однако современный мир вынужденно ускоряет Аанный процесс и не оставляет право выбора малочисленным народам. Вопрос отсутствия в российских документах строки о национальности не может не быть актуальным с точки зрения регистрации коренного населения.

Существенной угрозой для коренных малочисленных народов Российской Федерации явмяется и проблема их вытеснения с традиционных мест расселения, переселение на катастрофически непригодные места дмя проживания, полное ичезновение рабочих мест, уничтожение возможности заниматься традиџионными промыслами - дмя многих семей основного способа пропитания и выживания. Так, коренные народы России нередко оказываются в центре ресурсных конфииктов. Например, строительство газопровода на Ямале, цель которого до 2022 г. провести и ввести в экспиуатацию газопровоА Амя транспортировки «голубого» топмива из Новопортовска Ао точки, где соединяется система магистральных газопроводов от Ямбургского нефтегазоконденсантного месторождения транснациональной энергетической компании «Газпром». Углубление Ана реки и повышение соли в воде изменят систему микроорганизмов, что приведет к исчезновению рыбы и мишит основного заработка коренное население Ямала [11]. Еще один острый конфликт возник межАу компанией ОАО «Сургутнефтегаз» и компанией по добыче нефти в угодьях парка Нумто (Ханты-Мансийский автономный округ) [12] .

МежАународное законодательство Российской Федерации сегодня не представляет еАиной системы дия коренных малочисленных народов всех субъектов РФ, что явмяется политическим пробелом Аля внешней политики России в Арктическом регионе. Отсутствие четкой законодательной базы, нечеткий механизм фиксированного распределения бюджета, а также его цемевого освоения явцяются слабыми точками дмя России, так как именно территории и возможная добыча на них полезных ископаемых могут стать причиной утери влияния страны в Арктике. Унифицирование законодательной базы, ее ратификация и четкое исполнение представмяют собой базис Амя защиты территорий 
традиционного промысла коренных народов. Федеральный закон от 16 апремя 1999 г. № 194-Ф3 (в реА. от 13 июля 2020 г.) «О гарантиях прав коренных малочисленных народов Российской ФеАерации» преАставляет полный перечень прав и свобоА, способных урегулировать правовую защиту коренного населения, однако истинное положение вещей далеко от илеального сосуществования нефтепромышленных компаний и коренного населения. Порождение внутреннего сложного спора перерастает на уровень конфликта между крупным бизнесом ведущей отрасли страны и коренным малочисленным населением.

Разногласия во внутренней политике и внешнем состоянии Российской Федерации, например в Арктическом регионе, прослежкиваются через призму транснациональной идентичности коренного малочисленного народа саамов, прожкивающего на территории Королевства Норвегии, Республики Финляндии и Королевства Швеции [13]. Международный опыт поддержкки самоопределения этого народа доказывает, что именно благодаря признанию проблемы северные государства смогли подписать Саамскую конвенцию северных стран (официальный текст доступен только на шведском языке) путем представительства парламентов Королевства Швеция, Королевства Норвегия и Республикой Финляндия [14] . В данном документе отсутствует представительство саамов Российской Федерации Кольского полуострова и не упоминается его значимость на территории Северной Европы. К моменту подписания официального документа Аишь Республика Финцяндия опредемяла саамов как «коренной нароА» согласно Конституции страны (разА. 17 - право на собственный язык и культуру) [13] . Королевство Норвегия признавало саамский народ в качестве коренного только при наличии сводного пакета Аокументов, защищающих их права как национального меньшинства, но понятие «indegious people» («коренной наро丸») появилось мишь после принятия государством Саамской конвенции северных стран. Ситуаџия в Швеции схожа с Королевством Норвегия, так как саамы до Конвенции обладали мишь статусом национального меньшинства, несмотря на то что государство не раз подчеркивало важность вопроса определения понятийного аппарата, касающегося коренного народа [15] .

Принятие такого статуса и соответствующего документа на межгосударственном уровне осложняется из-за ратификации другого базового Аокумента Аля международного права, на котором основывается саамская конвенция, - Конвенции Международной организации труда (МОТ) № 169 «О коренных народах и народах, ведущих пяеменной

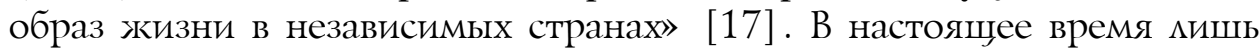
Королевство Норвегия является страной, полностью принявшей поцожения этого технического документа, однако офиџиальная версия 
Саамской конвенции северных стран основывается на данной Конвенции, что означает проникновение международного законодательства, касающегося коренных народов, в национальное законодательство Королевства Норвегия и Королевства Швеция [18] .

В главе IV Конвенции «Право саамов на землю и на воду» и раскрывающих ее статьях 34-40 закрепцяются права собственности саамов на территории распространения их самобытного ведения хозяйства, которое осуществляется в рамках их наџионального самоопределения, выстраивающегося вокруг их общей транснациональной идентичности. Конвенџия фактически признает их исключительное право на землепользование, а значит и право на собственность этих территорий, что помогает саамам не только сохранить оленеводство как самобытный промысел, но и вывести его на новый, более высокий уровень развития. Такая версия трактовки землепользования встречает в законодательствах северных стран серьезные вызовы, так как к моменту формирования и осознания коренным народом своей идентичности в государствах уже сушествовала законодательная база относительно земельного владения.

Российская Федерация не ратифицировала Конвенџию и не имеет саамского парламента на Кольском полуострове, создание которого оссложняется тем, что множество существующих неправительственных организаций саамов не создали еАиного представительного органа, способного обосновать проблемы регионального характера. Не опредемена и их территория в Арктическом регионе ввиду отсутствия соответствующих измерений и исследований, которые внесли бы ясность в этот важный внешнеполитический аспект деятельности Российской Федерации. Аействующий кишь в Королевстве Норвегия закон о Финнмарке (закон о правовых отношениях и управлении земельными и природными ресурсами в округе Финнмарк), введенный в ответ на прецедент, помогает развиваться оленеводству, однако не предусматривает защиту в случае несчастных случаев, а также выплату компенсаџий в случае утери пастбищных угодий [19]. Этот момент никак не отражается в документах по взаимодействию Саамского парламента Королевства Норвегия и национального парцамента государства.

В ст. 34 Саамской конвенции северных стран «Традиционное использование территориальных и водных ресурсов» оленеводство зафиксировано главным способом реализации национальной идентичности трансграничного народа, однако при этом не урегулирован территориальный вопрос распределения земель в Республике Финияндия, большей частью находящихся в собственности у государства [20]. Следовательно, правовой статус земельных владений и в Республике Финцяндия до сих пор остается на стадии неопределенности принадмежности саамским народным общинам. 
Российская Федерация в плане решения проблемы коренных народов по сути близка к Канаде, однако определенные различия все же имеются. Прежде всего в Канаде не проживает такое разнообразие коренного населения, как в России, однако общая численность в проџентах от общего населения превышает российский показатель. Основным законом Канады является Конституция страны, представленная составными частями (Конституционный акт 1867 г., Конституционный акт 1982 г., Канадская хартия прав и свобод) и конститущионными неписаными обычаями [18]. Процесс самоопределения коренного населения Канады начался с 1960-х годов, когда достижением и прорывом стало возникновение межплеменной организации Ассамблеи первых наций, которая стала частью политической жизни страны. Ассамблея к 1980 г. установила и добилась от местного управления прав на земли путем судебных разбирательств, одной из наиболее значимых побеА стала история земли Нунавут - региона инуитов на северо-западных территориях. Нунавут является большей частью Арктической территории Канады. ОАнако уровень жизни коренного населения остается несравнимо низким по сравнению с уровнем жизни остального населения, множество социальных вопросов не решается в связи с неурегулированным законодательством и нехваткой систематизаџии в регистрации коренного населения. Сходство с российскими реалиями наблюдается и в том, что принадмежность территории одному народу нельзя доказать без четкой систематизации законодательных актов, в то время как обоснованное доказательство территории Нунавут позволило начать процесс освоения канадской Арктической территории. Российская Федераџия явмяется местом жкительства и происхождения десятков разцичных коренных народов, чье представительство ограничивается мишь местным самоуправлением, что далеко от решения проблемы самоопределения.

Аля разрешения ситуаџии прежде всего необходимо найти механизм четкого определения принадлежности граждан к числу коренного малочисленного народа, причем не путем наделения полномочиями отдельный орган, а посреАством четкой систематизации ици возвращения строки «национальность» в паспорте гражданина Российской Федерации с указанием в ней национальности по мичному выбору гражАанина при получении. Требуется обновление и систематизация законодательства по поводу коренного малочисленного народа, так как сегодня спор о принадлежности арктических территорий осложняется многими факторами, среди которых вопросу самоопределения коренного населения принадлежит не последняя роль [21].

Обращение к опыту Канады и стран Северной Европы подтверждает необходимость создания отдельного органа, основанного на неправительс- 
твенных организациях коренного населения, на общинах. Существующие фонды и представительства через местное самоуправление и множество сообществ не имеют четкой стратегии, что не позволяет преАставителем коренного малочисленного населения находиться в социетальной безопасности. Объединенный орган представительства всех коренных народов Российской Федерации при систематизации законодательства может функщионировать по примеру Союза саамов в Республике Финцяндия или по канадскому примеру Ассамблеи первых наций. ОАнако российский вариант организации должен иметь законотворческую силу, так как именно через него путем экспертного мнения и научных исследований преАставмяется возможным защитить и доказать права владения территориями в Арктическом регионе Российской Федерацией во внешней политике.

Важен также экологический диалог между нефтедобывающими компаниями и преАставителями коренного малочисленного населения. Опыт выплаты денежных процентов от прибыли компаний во многих субъектах РФ показал положительные тенденции, однако подобная практика сегодня приостановлена, хотя ее возобновление может быть Аостаточно эффективным. При контроле наА деятельностью нефтеперерабатывающих компаний должно учитываться право голоса коренного населения, которое чаще всего отсутствует ввиду ненацаженной обратной связи межАу ними и преАставитемями бизнеса.

Реальное социально-правовое положение коренных малочисленных народов Российской Федерации расходится с представленным в официальных документах. Правовые отношения не всегда реализуются в полном объеме и соответствуют заявленному законодательному обоснованию. Более того, накопленный опыт реализации политики по отношению к коренным малочисленным народам выявцяет совершенно новые проблемы и угрозы, для отражения которых государства не имеют подготовменной законодательной базы [22]. Ни одно законодательство описываемых стран не имеет четко направленной, выстроенной политики реализаџии прав коренного малочисленного народа, так как часто создается путем оценивания произошедших прецедентов [23] . Опыт несогласованности законодательной базы страны является прямой предпосылкой дмя отдаленной перспективы унификации законов как внутри государства, так и в рамках внешнеполитического диалога [24].

Наџиональная идентичность коренного малочисленного народа Крайнего Севера Российской Федерации представляет собой инструмент выстраивания внешней политики по отношению к территориальным вопросам Арктического региона [25]. Взаимосвязь межАу внутренней политикой и внешним Аискурсом Аля оАного государства трансформируется во внешнеполитическое влияние путем проџесса защиты национальной идентичности. 
Международное представительство народов проявцяется в наличии неправительственных организаций, совместные усилия чиенов которых явмяются реальным инструментом выстраивания транснациональной идентичности, неизученной площадкой межкультурного диалога и возможным Аолгосрочным базисом Амя межАународного туризма. ОАнако разрозненность законодательных актов внутри северных стран отдаляет вопрос о таком диалоге на неопределенный срок. Более того, эти вопросы напрямую связаны с проявлениями нетерпимости по отношению к условиям природного пользования территориальными ресурсами. Игнорирование процессов несанкционированного использования земель традиционного промысла может привести не только к исчезновению коренных народов, но и к экологическим катастрофам, имеющим необратимые последствия.

\section{Библиографический список}

1. Конституция Российской Федерации (с изм. от 1 июля 2020 г.). URL: http:// www.constitution.ru/

2. О Едином перечне коренных малочисленных народов Российской Федерации: постановление Правительства РФ от 24 марта 2000 г. № 255 (в ред. от 26 мая 2020 г.). URL: http://www.consultant.ru/document/cons_doc_LAW_26631/0b18494d31d83a8c049a c37acc932f3df0a7634d/

3. Рамочная конвенция о защите национальных меньшинствах № 157. Совет Европы, Страсбург, 1996. URL: https://rm.coe.int/16800c1316

4. Indigenous and Tribal Peoples Convention. 27 June 1989 № 169, Geneva, 76th ILC session. URL: https://www.ilo.org/dyn/normlex/en/f?p=NORMLEXPUB:12100:0::NO:: P12100_ILO_CODE:C169

5. Guiding Principles on Business and Human Rights, Implementing the United Nations "Protect, Respect and Remedy" Framework New York and Geneva, 2011. URL: http:// www.saamicouncil.net/fileadmin/user_upload/Documents/Eara_dokumeanttat/GuidingPrinciplesBusinessHR_EN.pdf

6. Bloom W. Personal Identity, National Identity and International Relations. Cambridge: Cambridge University Press, 1996. P. 34-45.

7. Гарипов Р.Ш. Коренные малочисленные народы в России: гарантии прав и свобод // Журнал российского права. 2012. № 6.

8. Иванов В.М. Актуальные проблемы правового положения коренных малочисленных народов Севера // Молодой ученый. 2015. № 23.

9. О сухопутных территориях Арктической зоны Российской Федерации: Указ Президента РФ от 2 мая 2014 г. 2014. № 296. URL: http://www.kremlin.ru/acts/20895

10. Харлампьева Н.К. Эволюция понятия «Арктика» // Наука и образование. 2014. № 3. C. $23-45$.

11. Самсонова И.В., Павлова М.Б. Российский и международный опыт возмещения ущерба коренным малочисленным народам при ресурсном освоении территорий // Apктика XXI век. Гуманитарные науки. 2017. № 3 (13). С. 52-61.

12. Потравный И.М., Кривошапкина О.А., Попова И.М. Обоснование размера компенсаций коренным малочисленным народам Севера при реализации проектов 
на территориях их традиционной деятельности // Экономика природопользования. 2017. № 5. C. 65-82.

13. Finnmarksloven fra 3 Oktober 2018. Justis- og beredskapsdepartementet. URL: https:/www.regjeringen.no/no/tema/lov-og-rett/innsikt/finnmarksloven/id713353/

14. Hallituksen esitys eduskunnalle yksityistielaiksi ja erдiksi siihen liittyviksi laeiksi annetun hallituksen esityksen (HE 147/2017 vp) tдуdentдmisestд НЕ 11/2018// URL: https://www.eduskunta.fi/FI/vaski/KasittelytiedotValtiopaivaasia/Sivut/HE_11+2018.aspx

15. Dokumentasjon «Spillemidler samisk idrett» fra 7 Februar 2017. № 17/931. URL: https://innsyn.onacos.no/sametinget/mote/norsk/wfinnsyn.ashx?response=arkivsak_detalj er\&arkivsakid $=2017000931 \&$

16. Nordisk Samenkonvention Regeringarna i Finland, Norge och Sverige 13.01.2017. URL: https://www.sametinget.se/samekonvention

17. Конвенция о коренных народах и народах, ведущих племенной образ жизни в независимых странах № 169. Генеральная конференция Международной организации труда, 76-я сессия, 27 июня 1989 г. URL:http:/www.saamicouncil.net/fileadmin/ user_upload/Documents/Eara_dokumeanttat/D0\%9A \%D0\%9E\%D0\%9D\%D0\%92\%D0 $\% 95 \%$ D0\%9D $\%$ D0\%A6\%D0\%98\%D0\%AF_\%D0\%9C\%D0\%9E\%D0\%A2_169.pdf

18. Suomen perustuslaki. Oikeusministeriц, den 1 maaliskuu 2000 № 731. URL: http:// www.finlex.fi/fi/laki/ajantasa/1999/19990731

19. Декларация о правах лиц, принадлежащих к национальным или этническим, религиозным и языковым меньшинствам: принята резолюцией № 47/135 Генеральной Ассамблеи от 18 дек. 1992 г. URL: https://www.un.org/ru/documents/decl_conv/ declarations/minority_rights.shtml

20. Декларация ООН о правах коренных народов: принята Генеральной Ассамблеей от 13 сент. 2007 г. URL: https://documents-dds-ny.un.org/doc/UNDOC/GEN/ N06/512/09/PDF/N0651209.pdf?OpenElement

21. Европейская хартия региональных языков или языков меньшинств. Страсбург, 1992. 5 нояб. URL: https://www.coe.int/en/web/conventions/search-on-treaties/-/conventions/rms/090000168007c098

22. Международная конвенция о ликвидации всех форм расовой дискриминации: принята резолюцией № 2106 Генеральной Ассамблеи от 21 дек. 1965 г. URL: https:// www.un.org/ru/documents/decl_conv/conventions/raceconv.shtml

23. Nordisk Samenkonvention Regeringarna i Finland, Norge och Sverige 13.01.2017. URL: https://www.sametinget.se/samekonvention

24. Всероссийская перепись населения 2010 г. URL: http://www.gks.ru/free_doc/ new_site/perepis2010/croc/perepis_itogi1612.htm

25. Подосенова О. Коренные проблемы КМHC. URL: https://bellona.ru/2019/03/14/ korennye-problemy/

26. Justice Laws Website. URL: https://lois.justice.gc.ca/

27. Statistics Canada. URL: https://www.statcan.gc.ca/eng/start

28. Statistics Norway. URL: https://www.ssb.no/en

29. Statistikdatabasen. URL: http://www.statistikdatabasen.scb.se/pxweb/sv/ssd/

30. The Sameting comes to the Storting. 2015. Sept. 17. URL: https://www.stortinget. no/en/In-English/About-the-Storting/News-archive/Front-page-news/2014-2015/the-sameting-comes-to-the-storting1/ 